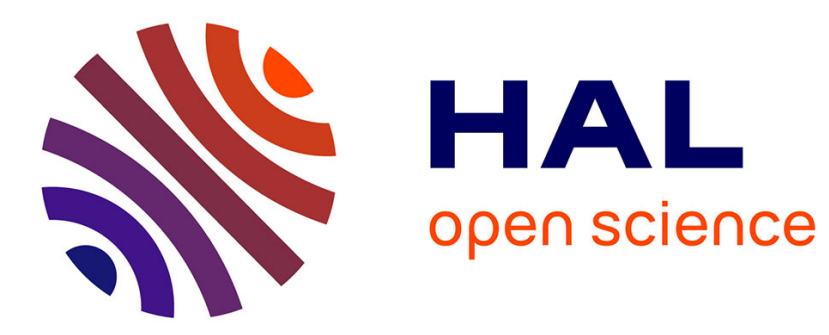

\title{
Relationship between Asian martial arts and health-related quality of life in Germany
}

Thomas Draxler, Herwig Ostermann, Wilfried Honekamp

\section{To cite this version:}

Thomas Draxler, Herwig Ostermann, Wilfried Honekamp. Relationship between Asian martial arts and health-related quality of life in Germany. Journal of Public Health, 2010, 19 (1), pp.57-64. 10.1007/s10389-010-0343-9 . hal-00561308

\section{HAL Id: hal-00561308 https://hal.science/hal-00561308}

Submitted on 1 Feb 2011

HAL is a multi-disciplinary open access archive for the deposit and dissemination of scientific research documents, whether they are published or not. The documents may come from teaching and research institutions in France or abroad, or from public or private research centers.
L'archive ouverte pluridisciplinaire HAL, est destinée au dépôt et à la diffusion de documents scientifiques de niveau recherche, publiés ou non, émanant des établissements d'enseignement et de recherche français ou étrangers, des laboratoires publics ou privés. 
Editorial Manager(tm) for Journal of Public Health Manuscript Draft

Manuscript Number: JOPH-D-10-00021

Title: Relationship between Asian martial arts and health-related quality of life in Germany

Article Type: Original Article

Corresponding Author: Mr. Thomas Draxler,

Corresponding Author's Institution:

First Author: Thomas Draxler

Order of Authors: Thomas Draxler; Herwig Ostermann, PhD, MSc; Wilfried Honekamp, PhD, MSc

Abstract: Aim: Due to of the steady increase in health care costs, a greater focus on maintaining wellness and preventing health issues has been established. Historically, Asian martial arts were closely associated with maintaining healthfulness. Thus, the aim of this investigation was to determine if people who practice Asian martial arts gain any health-related quality of life benefits compared to the general population.

Subject and Methods: Therefore, 343 martial artists practicing eight varieties of martial arts answered the German standardized questionnaire 36 in a controlled setting at 24 martial arts schools 3 schools per martial art) between February 2008 and July 2008. These participants were not given information regarding the purpose of the study. Additionally, between July 2008 and December 2008, 2512 martial artists completed an online version of German standardized questionnaire 36.

Results: The results of those completing the questionnaire in person differed from those responding to the online questionnaire. Compared to the general public, both martial arts groups rated their healthrelated quality of life to be better. Of the parameters evaluated, the greater differences were observed for physical aspects of health than for psychological aspects.

Conclusion: Thus, these results indicate that participation in martial arts provides health-related quality of life benefits associated with the prevention of health problems. However, further studies are needed to understand the complex relationship between the practice of martial arts and improved health. 


\title{
Relationship between Asian martial arts and health- related quality of life in Germany
}

\author{
${ }^{1}$ PhD Student, The Health and Life Sciences University Hall/Tyrol, Department for \\ Human and Economic Sciences, Eduard Wallnöfer-Zentrum 1, 6060 Hall/Tyrol, \\ Austria \\ ${ }^{2}$ Professor, The Health and Life Sciences University Hall/Tyrol, Department for \\ Human and Economic Sciences, Eduard Wallnöfer-Zentrum 1, $6060 \mathrm{Hall} /$ Tyrol, \\ Austria \\ ${ }^{3}$ Lecturer, University of Applied Sciences Bremen, Electrical Engineering and \\ Computer Science Faculty, Flughafenallee 10, 28199 Bremen, Germany
}

\section{Corresponding author}

\section{Thomas Draxler}

The Health and Life Sciences University Hall/Tyrol

Department for Human and Economic Sciences

Eduard Wallnöfer-Zentrum 1

$6060 \mathrm{Hall} / \mathrm{Tyrol}$

Austria

E-Mail: thomas.draxler@umit.at

Tel: $\quad+43(0) 5086483880$

Fax: $\quad+43(0) 508648673880$ 


\begin{abstract}
Aim: Due to of the steady increase in health care costs, a greater focus on maintaining wellness and preventing health issues has been established. Historically, Asian martial arts were closely associated with maintaining healthfulness. Thus, the aim of this investigation was to determine if people who practice Asian martial arts gain any health-related quality of life benefits compared to the general population.

Subject and Methods: Therefore, 343 martial artists practicing eight varieties of martial arts answered the German standardized questionnaire 36 in a controlled setting at 24 martial arts schools (3 schools per martial art) between February 2008 and July 2008. These participants were not given information regarding the purpose of the study. Additionally, between July 2008 and December 2008, 2512 martial artists completed an online version of German standardized questionnaire 36.

Results: The results of those completing the questionnaire in person differed from those responding to the online questionnaire. Compared to the general public, both martial arts groups rated their health-related quality of life to be better. Of the parameters evaluated, the greater differences were observed for physical aspects of health than for psychological aspects.
\end{abstract}

Conclusion: Thus, these results indicate that participation in martial arts provides healthrelated quality of life benefits associated with the prevention of health problems. However, further studies are needed to understand the complex relationship between the practice of martial arts and improved health.

\title{
Keywords
}

Martial arts, primary prevention, health-related quality of life, German standardized questionnaire 36 


\section{Introduction}

Currently, Asian martial arts are practiced by many thousands of Germans in all age groups. The largest association, with more than over 200,000 members, is the Judo Federation, followed by the Karate Association ( 110,000 members), the Jujutsu Association ( 60,000 members), and the Taekwondo Union ( 45,000 members). Each of the martial arts schools are organized by the corresponding associations, but are also supplemented by both commercial and private institutions and organizations. Further, the vast number of different martial arts styles available throughout Germany underlines the popularity of this sport.

In addition to the common martial arts styles like Judo, Karate, Jujutsu and Tae Kwon Do (TKD), other lesser known styles, such as Esdo, Kendo or Wing Tsun, are also practiced. Further, there are enumerable rare styles of martial arts practiced, making it impossible to fully account for all of the different martial arts styles available in Germany. The interest of this study was to determine if those who practice Asian martial arts feel healthier - physically and psychologically - than the rest of the German population.

There has been a steady increase in health care costs in Germany over the last several years. In 2007, the cost of health care was approximately 252.8 billion Euros, which represents a $3.2 \%$ (or 7.8 billion Euros) increase over the previous year. Per person, these health care costs are $10.4 \%$ of the gross domestic product (or 3,070 Euros) per household and are slightly higher than previous years (2970 Euros and 2900 Euro in 2006 and 2005, respectively). Between 2000 and 2006 health care costs increased only $1.4 \%$ per person in Germany. This relatively slow rise in health care costs was partially due to the implementation of cost-reducing health care reform (Federal Statistical Office 2007). Given the continued increase in health care costs in Germany, ways to stimulate a broader sense of health-consciousness among the general population, as well as developing strategies for the prevention of health problems, have gained focus in political and social arenas (SPD/Greens 2005).

The Ottawa Charta WHO (1986) is regarded as a milestone of modern illnessprevention and health promotion. Preventing health-related issues and promoting wellness have become broadly relevant social topics and active areas of research. The Federal Ministry of Education and Research (BMBF 2006) in Germany has recognized the importance of primary prevention, which refers to any prophylaxis that is able to prevent an illness from occurring. This includes education for managing individual health risks and support/treatment aimed at changing high-risk behavior. Rosenbrock (2008) believes that improvements in primary prevention efforts are necessary to adequately face upcoming challenges in health politics. However, the BMBF states that the number of studies that measure the effectiveness and efficiency of primary prevention and health promotion are 
insufficient. Superior indicators and devices of elevation used to determine the quality of structure, process and result are still to be developed.

Asian martial arts have a tradition and culture dating back several thousand years. In addition to the physical aspects of martial arts, traditional martial arts training programs also include the teaching of social values and methods to establish and maintenance of health. For example, part of the original martial arts curriculum included respecting creation, treating your fellow men right and peacefully, obtaining from alcohol and tobacco, moderating your eating habits, and the regular practice of meditation techniques (Dolin, Popow, Tolstikow 1988).

The concepts taught through martial arts are similar to the primary prevention concepts established by the German compulsory health insurance companies. Their head organizations have defined the standard primary spheres of preventive activity, such as motion, nutrition, relaxation, handling strain, prevention of addiction, and the general competence of life (Head organization of health insurances 2008). Since these ideas are all covered by martial arts education, the practice of Asian martial arts could be one means to improve the health standards of the German population and therefore help to reduce public health care costs.

Present studies show only what impacts the practice of martial arts can have on the person's psychological and physical health. A study by Held (2004) that examined 180 people showed the practice of TKD provided a positive impact on the person's subjectively felt state of health. Participants reported that they had more energy and felt less stressed than before the workout. A report by Binder et al. (2007) showed that several investigations over the last 30 years about the health benefits of martial arts had concluded that positive psychosocial changes are observed in people practicing martial arts. In contrast, three studies did not detect any changes (positive or negative) in the participants and three other studies showed that martial arts training has a negative impact on healthfulness. It is widely held that including only the physical aspects of martial arts training and omitting the teaching of ethnical and moral values is responsible for the observed negative impacts. Although this question remains unanswered, martial arts are viewed as potential alternative or additional therapy to treat mental-health problems. The benefit of martial arts for mental-health problems was supported by a case study by Weiser, Kutz I, Kutz S, and Jacobson (1995). Further, studies by Terry (2006) and Bitzer-Gavornik and Unterrainer (2006) on Karate show that athletes of different ages consider themselves to be mentally tougher.

Other studies have shown that breaking off training has an opposite effect on the psychology of advanced karate athletes. Both males and females reported increased anger, negative emotions, depression, and noticed strain and mood swings (Szabo 2001). While in 
other studies, martial artists were found to not be more violent (Grabert 2001) and did not display increased aggression (Hoffmann 2006).

The risk of injury associated with martial arts could be seen as a negative factor for the prevention of health issues. The number of injury experience by 263 martial artists coming from five different styles was investigated by Zetaruk, Violán, Zurakowski, Micheli (2005). Athletes who practiced TKD had a risk of injury three-times higher than those who practiced Shotokan Karate or Kung Fu. The number of injuries was similar between males and females. Burke, Barfoot, Bryant, Schneider, Kim, and Levin (2003) investigated the number of injuries during a Taekwondo tournament with 2498 participants. Previous tournaments had a rate of injury as high as $25 / 1000$ to $12.7 / 100$; however, this tournament had a $0.4 / 1000$ rate of injury. These authors concluded that TKD was safer than other martial arts styles as long as the required security measures are maintained.

Parzeller and Raschka (2003) performed a 20-year long study (1981-2000) on 2969 cases of unexpected deaths Germany associated with sports. The finding showed no martial artists among these casualties. Instead, the greatest number of deaths were associated with soccer $(n=919)$, tennis $(n=209)$, and cycling $(n=187)$. Thus, martial arts have been extensively investigated in several studies that analyzed different problems from different points of view.

Many of these investigations have definitively shown an improvement of the athlete's physical condition over that of people who do not practice martial arts. However, the above studies have not determined whether martial artists are healthier and more resistant to illnesses than those who do not participate in sport. Therefore, the aim of this investigation was to determine if there are additional health-related quality of life benefits observed in those who practice martial artists compared to the general population.

\section{Method and procedure}

From February 2008 to June 2009, 343 martial artists practicing eight different martial arts styles from 24 different schools answered the German standardized questionnaire 36 (SF-36) questionnaire in a controlled setting and without prior knowledge of the aim of the evaluation. To guarantee objectivity, the questionnaire was given before training in each of the schools. The authors of this paper, as well an informed fellow student who had not participated in any martial arts prior to conducting the study, supervised the procedure.

Additionally, from June 2008 to December 2008, 2512 martial artists answered the online questionnaire found on the website www.forschung-kampfsport.de (investigation in 
martial arts). The IP-address of each responder was recorded to increase transparency and limit the possibility of external manipulation.

Approximately 4000 e-mails were sent to associations, schools, and individual martial artists inviting people to participate in the project. Furthermore, announcements appeared in the magazines "Fitness Tribune" and "Kampfkunst International" (Martial Arts International), as well as on the website www.kampfsport-deutschland.de (martial arts in Germany). Several associations and martial arts schools added the above link to their websites to promote the project.

The in-person questionnaire had martial artists describe themselves in regard to their health-related quality of life based on the SF-36. The SF-36 is the most frequently used international standard method of evaluating a person's health. It contains 36 items, 35 out of which belong to the following eight scales:

1. Physical Operational Capability (10 Items)

2. Physical Role Function (4 Items)

3. Physical Pain (2 Items)

4. Average Cognition of Health (5 Items)

5. Vitality (4 Items)

6. Social Operational Capability (2 Items)

7. Emotional Rola Function (3 Items)

8. Psychological Well-being (5 Items)

This questionnaire covers the multidimensionality of a person's state of health, including their psychological and physical cognition, social relations, and functional competence. Common treatments like the energetic terminal point diagnosis (Mandel 1990), blood examinations, and more involved physical methods of evaluating the participants were not used because the intent of this study was to examine a large cross-section of a variety of martial arts styles in Germany. Therefore a procedure including physical treatments would be too complex for a large sample size.

After consulting with experts in the area of illness prevention from accident and health insurance agencies, additional question were developed and added to the SF-36 questionnaire. These questions were also answered by the participants. The use of the SF36 questionnaire with additional questions was designed to show any gain of cognition through the practice of martial arts. The question regarding the change of the state of health in relation to the last year is not integrated in any scale and is evaluated separately (Bullinger 1998, p. 51-62). Further, different criteria, such as the number of participants that practiced each style of martial arts were recorded to show the demographics of the sample population. Including a variety of styles with different cultural backgrounds and histories of development 
into the design of the investigation was regarded as very important. Martial artists could only participate in the online questioning after naming their style of martial arts.

Table 1: Martial arts representation in Present and Online groups

\begin{tabular}{|c|c|c|c|c|c|}
\hline & & Frequency & Percentage & Valid Percentage & Cumulative Percentage \\
\hline & $\begin{array}{l}\text { Esdo Present } \\
\text { Esdo Online }\end{array}$ & $\begin{array}{l}55 \\
93\end{array}$ & $\begin{array}{l}16.0 \\
3.7\end{array}$ & $\begin{array}{l}16.0 \\
3.7\end{array}$ & $\begin{array}{l}16.0 \\
3.7\end{array}$ \\
\hline & $\begin{array}{l}\text { Aikido Present } \\
\text { Aikido Online }\end{array}$ & $\begin{array}{l}35 \\
200\end{array}$ & $\begin{array}{l}10.2 \\
8.0\end{array}$ & $\begin{array}{l}10.2 \\
8.0\end{array}$ & $\begin{array}{l}26.2 \\
11.7\end{array}$ \\
\hline & $\begin{array}{l}\text { WingTsun Present } \\
\text { Wing Tsun Online }\end{array}$ & $\begin{array}{l}37 \\
228\end{array}$ & $\begin{array}{l}10.8 \\
9.1\end{array}$ & $\begin{array}{l}10.8 \\
9.1\end{array}$ & $\begin{array}{l}37.0 \\
20.7\end{array}$ \\
\hline & $\begin{array}{l}\text { Judo Present } \\
\text { Judo Online }\end{array}$ & $\begin{array}{l}39 \\
197\end{array}$ & $\begin{array}{l}11.4 \\
7.8\end{array}$ & $\begin{array}{l}11.4 \\
7.8\end{array}$ & $\begin{array}{l}48.4 \\
28.6\end{array}$ \\
\hline & $\begin{array}{l}\text { Jujutsu Present } \\
\text { Jujutsu Online }\end{array}$ & $\begin{array}{l}33 \\
255\end{array}$ & $\begin{array}{l}9.6 \\
10.2\end{array}$ & $\begin{array}{l}9.6 \\
10.2\end{array}$ & $\begin{array}{l}58.0 \\
38.7\end{array}$ \\
\hline Valid & $\begin{array}{l}\text { Karate Present } \\
\text { Karate Online }\end{array}$ & $\begin{array}{l}54 \\
672\end{array}$ & $\begin{array}{l}15.7 \\
26.8\end{array}$ & $\begin{array}{l}15.7 \\
26.8\end{array}$ & $\begin{array}{l}73.7 \\
65.5\end{array}$ \\
\hline & $\begin{array}{l}\text { Taekwondo Present } \\
\text { Taekwondo Online }\end{array}$ & $\begin{array}{l}53 \\
248\end{array}$ & $\begin{array}{l}15.5 \\
9.9\end{array}$ & $\begin{array}{l}15.5 \\
9.9\end{array}$ & $\begin{array}{l}89.2 \\
75.4\end{array}$ \\
\hline & $\begin{array}{l}\text { Kendo Present } \\
\text { Kendo Online }\end{array}$ & $\begin{array}{l}37 \\
156\end{array}$ & $\begin{array}{l}10.8 \\
6.2\end{array}$ & $\begin{array}{l}10.8 \\
6.2\end{array}$ & $\begin{array}{l}100.0 \\
81.6\end{array}$ \\
\hline & Philippine Martial Arts Online & 66 & 2.6 & 2.6 & 84.2 \\
\hline & Kickboxing Online & 80 & 3.2 & 3.2 & 87.4 \\
\hline & Kung Fu Online & 84 & 3.3 & 3.3 & 90.7 \\
\hline & Miscellaneous Online & 233 & 9.3 & 9.3 & 100.0 \\
\hline & $\begin{array}{l}\text { Entire Present } \\
\text { Entire Online }\end{array}$ & $\begin{array}{l}343 \\
2512\end{array}$ & $\begin{array}{l}100.0 \\
100.0\end{array}$ & $\begin{array}{l}100.0 \\
100.0\end{array}$ & \\
\hline
\end{tabular}

Importantly, differences observed for martial arts styles between the in-person (Present) group and the Online group result from the use of a layered sample method for the Present questioning procedure. The average age in the groups were 31.9 and 30.6 year for the Present $(n=343)$ and Online $(n=2512)$ groups, respectively, and were lower than the general population comparison group (47.6 years; $n=2906$ ). The educational background was higher for the martial artists. Furthermore, there was a difference between both sexes. In the Present group, $74.1 \%$ were men, $24.4 \%$ were women, and $1.5 \%$ did not specify their gender; in the Online group, $74.9 \%$ were men and $25.1 \%$ were women, and in the comparison group $44.4 \%$ were men and $55.6 \%$ were women. The average amount of training performed weekly for the Present and Online groups was 3.4 and 4.7 hours, respectively. 


\section{Results}

\section{Table 2}

Comparison of Standard control group with Present group, Online group, and Combined Present and Online groups (Entire)

\begin{tabular}{|c|c|c|c|c|c|}
\hline & Type & $\mathbf{N}$ & Mean & Standard deviation & $\begin{array}{l}\text { p value }+ \\
\text { Sig. }(1 \text {-sided })\end{array}$ \\
\hline \multirow[b]{2}{*}{$\begin{array}{l}\text { SF-36 Physical operational capability } \\
(0-100)\end{array}$} & Standard & 2906 & 85.4061 & 22.49627 & .000 \\
\hline & $\begin{array}{l}\text { Present } \\
\text { Online } \\
\text { Entire }\end{array}$ & $\begin{array}{l}343 \\
2512 \\
2855\end{array}$ & $\begin{array}{l}95.8529 \\
93.0018 \\
93.3443\end{array}$ & $\begin{array}{l}7.89559 \\
14.15667 \\
13.58879\end{array}$ & $\begin{array}{l}.000 * * \\
.000 * * \\
.000 * *\end{array}$ \\
\hline \multirow[b]{2}{*}{ SF-36 Physical function (0-100) } & Standard & 2900 & 82.6041 & 32.91789 & .000 \\
\hline & $\begin{array}{l}\text { Present } \\
\text { Online } \\
\text { Entire }\end{array}$ & $\begin{array}{l}343 \\
2512 \\
2855\end{array}$ & $\begin{array}{l}95.1373 \\
89.1699 \\
89.8868\end{array}$ & $\begin{array}{l}16.71499 \\
25.67206 \\
24.84136\end{array}$ & $\begin{array}{l}.000 * * \\
.000 * * \\
.000 * *\end{array}$ \\
\hline \multirow[b]{2}{*}{ SF-36 Physical pain (0-100) } & Standard & 2908 & 78.8336 & 27.54676 & .000 \\
\hline & $\begin{array}{l}\text { Present } \\
\text { Online } \\
\text { Entire }\end{array}$ & $\begin{array}{l}343 \\
2512 \\
2855\end{array}$ & $\begin{array}{l}86.9684 \\
79.9413 \\
80.7855\end{array}$ & $\begin{array}{l}16.51923 \\
23.88882 \\
23.23817\end{array}$ & $\begin{array}{l}.000 * * \\
.000 * * \\
.000 * *\end{array}$ \\
\hline \multirow[b]{2}{*}{$\begin{array}{l}\text { SF-36 Average cognition of health } \\
(0-100)\end{array}$} & Standard & 2913 & 68.0338 & 20.63557 & .000 \\
\hline & $\begin{array}{l}\text { Present } \\
\text { Online } \\
\text { Entire }\end{array}$ & $\begin{array}{l}343 \\
2512 \\
2855\end{array}$ & $\begin{array}{l}79.4088 \\
75.7795 \\
76.2156\end{array}$ & $\begin{array}{l}11.73618 \\
19.61551 \\
18.87920\end{array}$ & $\begin{array}{l}.000^{* *} \\
0.50 \\
.000^{* *}\end{array}$ \\
\hline \multirow[b]{2}{*}{ SF-36 Vitality (0-100) } & Standard & 2894 & 63.2480 & 18.52809 & .000 \\
\hline & $\begin{array}{l}\text { Present } \\
\text { Online } \\
\text { Entire }\end{array}$ & $\begin{array}{l}343 \\
2512 \\
2855\end{array}$ & $\begin{array}{l}64.6455 \\
60.8065 \\
61.2677\end{array}$ & $\begin{array}{l}12.01420 \\
18.15372 \\
17.57287\end{array}$ & $\begin{array}{l}.029 * \\
.109 \\
.183\end{array}$ \\
\hline \multirow[b]{2}{*}{$\begin{array}{l}\text { SF-36 Social operational capability } \\
(0-100)\end{array}$} & Standard & 2913 & 88.8027 & 18.34065 & .000 \\
\hline & $\begin{array}{l}\text { Present } \\
\text { Online } \\
\text { Entire }\end{array}$ & \begin{tabular}{|l}
343 \\
2512 \\
2855
\end{tabular} & $\begin{array}{l}87.6796 \\
88.3542 \\
88.2731\end{array}$ & $\begin{array}{l}14.23899 \\
14.89307 \\
14.81522\end{array}$ & $\begin{array}{l}.091 \\
.000^{* *} * \\
.000^{* *}\end{array}$ \\
\hline \multirow[b]{2}{*}{ SF-36 Emotional function (0-100) } & Standard & 2902 & 89.4719 & 26.96125 & .000 \\
\hline & $\begin{array}{l}\text { Present } \\
\text { Online } \\
\text { Entire }\end{array}$ & $\begin{array}{l}343 \\
2512 \\
2855\end{array}$ & $\begin{array}{l}94.4832 \\
81.1596 \\
82.7603\end{array}$ & $\begin{array}{l}16.13849 \\
32.00766 \\
30.84390\end{array}$ & $\begin{array}{l}.000 * * \\
.000 * * \\
.000 * *\end{array}$ \\
\hline \multirow[b]{2}{*}{$\begin{array}{l}\text { SF-36 Psychological well-being (0- } \\
\text { 100) }\end{array}$} & Standard & 2906 & 73.8195 & 16.76168 & .000 \\
\hline & $\begin{array}{l}\text { Present } \\
\text { Online } \\
\text { Entire }\end{array}$ & $\begin{array}{l}343 \\
2512 \\
2855\end{array}$ & $\begin{array}{l}77.6868 \\
70.7263 \\
71.5626\end{array}$ & $\begin{array}{l}10.25162 \\
20.45838 \\
19.64588\end{array}$ & $\begin{array}{l}.000 * * \\
.000 * * \\
.000 * *\end{array}$ \\
\hline \multirow[b]{2}{*}{ ROH SF-36 change of health } & Standard & 2914 & 2.9044 & .98696 & .000 \\
\hline & $\begin{array}{l}\text { Present } \\
\text { Online } \\
\text { Entire }\end{array}$ & $\begin{array}{l}343 \\
2512 \\
2855\end{array}$ & $\begin{array}{l}2.3920 \\
2.4752 \\
2.4652\end{array}$ & $\begin{array}{l}.79594 \\
.99311 \\
.97179\end{array}$ & $\begin{array}{l}.000 * * \\
.000 * * \\
.000 * *\end{array}$ \\
\hline
\end{tabular}

Standard = general population control group; Present $=$ group who completed questionnaire in person; Online = group who completed questionnaire online; Entire $=$ Present + Online groups . + There is heterogeneity of variance within all t-tests.

Significance $*(p<0.05) * *(p<0.001)$ 
The mean values for the questionnaire answers for the groups individually (Present and Online) or combined (Entire), which was weighted with respect to age, education, and sex, and the comparison group (Standard) underwent t-tests to determine significant differences between groups. The results are presented in Tables 2 and 3.

\begin{tabular}{|c|c|c|c|c|c|}
\hline & Type & $\mathbf{S}$ & Mean & Standard deviation & $\begin{array}{l}\text { p value }+ \\
\text { Sig. }(1 \text {-sided })\end{array}$ \\
\hline \multirow[t]{2}{*}{ STANDARD. Physical amount scale } & Standard & 2868 & 50.0042 & 10.46447 & .000 \\
\hline & $\begin{array}{l}\text { Present } \\
\text { Online } \\
\text { Entire }\end{array}$ & $\begin{array}{l}343 \\
2512 \\
2855\end{array}$ & $\begin{array}{l}54.9039 \\
53.9320 \\
54.0488\end{array}$ & $\begin{array}{l}4.34939 \\
7.53140 \\
7.22992\end{array}$ & $\begin{array}{l}.000 * * \\
.000 * * \\
.000 * *\end{array}$ \\
\hline \multirow{2}{*}{$\begin{array}{l}\text { STANDARD. Psychological amount } \\
\text { scale }\end{array}$} & Standard & 2868 & 51.4362 & 8.34471 & .000 \\
\hline & $\begin{array}{l}\text { Present } \\
\text { Online } \\
\text { Entire }\end{array}$ & $\begin{array}{l}343 \\
2512 \\
2855\end{array}$ & $\begin{array}{l}51.2193 \\
48.0615 \\
48.4409\end{array}$ & $\begin{array}{l}5.34598 \\
10.25729 \\
9.85122\end{array}$ & $\begin{array}{l}.254 \\
.000^{* *} \\
.000 * *\end{array}$ \\
\hline
\end{tabular}

Standard = general population control group; Present = group who completed questionnaire in person; Online $=$ group who completed questionnaire online; Entire $=$ Present + Online groups .

+ There is heterogeneity of variance within all t-tests.

Significance $*(\mathrm{p}<0.05) * *(\mathrm{p}<0.001)$

The data from the SF-36 questionnaire allow a quantitative comparison of the subjective evaluation of health from the point of view of the interviewees. Compared to the general population (Standard), the martial artists from both the Present and Online groups report a higher degree is health and are closer to the ideal values for a healthy person. The most striking differences were observed for categories dealing with physical functions. Further, there were different results between the Present and Online groups and both martial artist groups and the comparison group.

Difference between the Present and Online groups originate from the different basic conditions and context of the questionnaire. The participants who completed the questionnaire in-person rated their subjective health condition directly before a martial arts training session and therefore were in a different physical, hormonal, and psychological context than the online interviewees. Additionally, the participants who completed the online questionnaire did so at different times of the day. Finally, seasonal effects could have altered the results, since the Present group completed the questionnaire during FebruaryJuly and the online questionnaire was completed during July-December.

There were also differences in the composition of the Present and Online groups, as listed in Table 1. The martial art Esdo is a small association with approx. 15,000 members. Esdo refers to itself as a sport of health and defense. This group represents $16.0 \%$ of the Present group and only $3.7 \%$ of the Online group. Differences were also seen for those practicing Karate. This particular style was practiced by $15.7 \%$ of the Present group and 
$26.8 \%$ of the Online group. In addition, $18.4 \%$ of martial artists responding to the online questionnaire practiced styles such as Kick Boxing or Philippine martial arts, which were not represented in the questioning of interviewees in-person at martial arts schools.

On the questionnaire, the 'Physical function' refers to the impact a person's physical health condition has on that person's daily work or activity. The mean of the 'Physical function' of the Present group was significantly higher (12.53) than that of the Standard group $(p<0.05)$. Further, while the mean of the Online group was also significantly higher (6.56) than the Standard group $(p<0.05)$, the Present group had an overall better score than the Online group.

The 'Physical operational capability' provides a measure of everyday physical activities, such as self-supply, hoisting, stooping, climbing stairs, as well as medium heavy or exhausting actions. In this category, there was also a highly significant difference of 10.45 between the Present group and the Standard group $(p<0.05)$. The difference between the Online group and the Standard group was 7.59. This was also a significant difference $(p<0.05)$ but less than the Present group by 2.85 .

The subject areas 'Physical pain' and 'Average cognition of health' are part of the 'Physical amount scale'. The Present group was 8.13 and 11.37 points better than the Standard group for 'Physical pain' and 'Average cognition of health', respectively. These were also significant differences $(p<0.05)$. For 'Physical pain', the results of the Online group were 1.10 better than the Standard group but 7.02 worse than the Present group. Further, in the 'Average cognition of health' category the Online group was 7.74 better than the Standard group but 3.62 lower than the Present group. The difference between the Online group and the Standard group for the 'Physical pain' category was significant $(p<0.05)$ but for 'Average cognition of health' the difference did not reach statistical significance.

The results of the Present group for the 'Psychological amount scale' as well as in the 'Health changes in comparison to the previous year' category are not as clear as those of the 'Physical amount scale'. Parts of the 'Psychological amount scale' are: Vitality, Social operational capability, Emotional function, and Psychological well-being. There was no significant difference for the 'Psychological amount scale' between the Present group and the Standard group ( $p>0.05$ ); however, there was a significant difference between the Online group and the Standard group $(p<0.05)$. Further, there were significant differences between the Online group and the Standard group for the subcategories of the 'Psychological amount scale'. Specifically, there was a 5.01 difference in 'Emotional function' $(p<0.05)$ and a 3.86 difference in 'Psychological well-being' $(p<0.05)$. There were no significant differences for the 'Vitality' and 'Social operational capability' categories for the Online and Present groups, respectively. 


\section{Discussion}

An exemplary evaluation of the health insurance company Innungskrankenkasse (Guild Health Insurance Company) Baden-Württemberg, which included 753 test persons showed no backed findings but a tendency that persons using primary prevention methods had improved health-related quality of life. The longitudinal evaluation with additional questions taken from the SF-36 questionnaire could detect that all dimensions of healthrelated quality of life significantly improved while the persons were enrolled in exercise and relaxation courses. However, the sustainability and the stability of these effects were not evaluated (Riemann \& Gläser 2001). In the 'activity' primary prevention sphere used by the compulsory health insurance agencies, activities like cardiovascular trainings, workouts for the back and spine, walking, aqua-jogging, Qigong, Tai Chi, Yoga, autogeous training, progressive relaxation of muscles, and others have been promoted. Except for Qigong and Tai Chi, martial arts have not been recommended as primary preventive measures (TKK 2006).

The current study was conducted to determine if martial arts qualify as a primary prevention activity. The suitability of martial arts as primary prevention measures can only be recommended if people who practice martial arts are actually healthier then people who do not. However, a person's state of health is not an easily defined concept. Rather it is a complicated interaction of many factors that require overall health to be examined from a multidimensional point of view. Thus, we developed a questionnaire that considered multiple parameters associated with health-related quality of life and considered psychological wellbeing, physical condition, social relations, and functional competence.

The results indicate that those who participate in any kind of martial art perceive their healthrelated quality of life to be better than those in the general population. However, it is necessary to look closer at the different dimensions before making an overall assessment. Compared to the Standard group, who did not practice martial arts, those who practiced martial arts scored significantly better on the questionnaire overall. This result confirms the results of other studies that reported practicing martial arts improves the person's psychological constitution. Importantly, for the psychological assessment in the present study significant improvement in the Present group was only observed in the 'Emotional role function' and the 'Psychological well-being' categories.

A 30-year longitudinal study by Binders (2007) showed that positive psychosocial changes in people who practice martial arts were always observed. In contrast, the present study shows that a sophisticated picture of the health promoting effects of martial arts can be constructed by including a series of questions that evaluate multiple aspects of psychological well-being. We assume that there is a complex relationship between practicing martial arts 
regularly and any possible psychosocial benefits. For instance Dorscher and Preuß (2005) elevated 50 martial artists and reported that focusing only on physical training for martial arts competitions did not provide a positive change to the athlete's psychological health. Thus, the success of a martial arts program for primary prevention may hinge on the scope of the training program. A broad program that includes social, spiritual, and physical aspects may be superior to a more narrow, purely physical training program designed to prepare an athlete for a competition. Thus, the relationship between the practice of martial arts and improved health likely includes other influences. For instance, the ultimately goals of the training, as well as the social and occupational surroundings of the person may have a deeper impact on their social operational capability than the physical movements of the martial arts itself.

Research on a person's quality of life traditionally requires the person to be present, in-person, and to complete a paper questionnaire. However, due to factors such as costs and time constraints, numerous studies have been adapted to utilize the Internet to collect data. One complication of this is that internet based data gathering can influence the subject's answers; though most studies do not report differences among the answers given between in-person and online participants (Kongsved, Basnov, Holm-Christensen, Hjollund 2007). Because of that, the present study was conducted using both questionnaires completed by participants in-person and those completing an online questionnaire. These two questionnaires were administered at different times. The results were compared according to the type of questionnaire and compared individually or as a whole to a standard group (Tables 2 and 3 ).

The different results between the Present and Online groups could result from differences in the styles of martial arts practiced by the groups or differences in the participant's behavior/activity prior to completing the questionnaire. No difference in sex or relationship status was seen between the Present and Online groups. However, there were behavior related differences between the groups, such as: voluntary work: Present $33.5 \%$ and Online 45.7\%; smoking: Present 7.6\% and Online 15\% Further, the Online group practiced martial arts 1.3 hours more each week, on average, than the Present group. Of the Online group, $78.2 \%$ practiced martial arts at a licensed nonprofit association, whereas in the Present group $61.5 \%$ practiced martial arts at a licensed nonprofit association and $38.5 \%$ did so in a private school. Finally, there were religion-related differences. In the Present group, $59.2 \%$ identified themselves as religious, while only $45.9 \%$ of the Online group interviewees identified themselves as religious. Thus, in addition to difference in the martial arts styles, differences in behavior and religious beliefs were observed between the groups and between those practicing a martial art and the Standard group. Kral (2009) obtained similar results in a recent report examining health-related effects of Karate in Austria. She concluded that the 
Asian concept of exercise can be used as a multiple health-factor promoting instrument,

\section{Limitations}

The complex subject matter in this study represents the most significant limitation. The present investigation on a cross-section of the martial arts practitioners in Germany indicates that the practice of martial arts has the potential for overall health benefits. This can only be confirmed through a longitudinal study that looks at both subjective and objective measures of health, resistance to illness, and injury rates. The SF-36 questionnaire used in this study is one of the most frequently used devices for measuring a person's subjective quality of life. The questionnaire's psychometric criteria, such as reliability and validity, are rated as 'excellent' and are accepted as an adequate instrument for measuring a person's health-related quality of life (Bullinger 1998 P. 32).

While the differences between both the Present and Online groups with the representative German Standard sample were statistically significant, the evaluation endpoint was the subjective "health-related quality of life". This is not rigorous enough to establish martial arts as a suitable primary prevention activity. Further studies that include historic, physical, and technical investigations of subjects are required to establish whether Asian martial arts are suitable as a health prevention method.

\section{Conclusion}

The present study shows that 343 martial artists from eight different styles, when questioned in-person, had higher health-related quality of life scores than the average population. A greater difference was seen for physical aspects of the questionnaire than for psychological aspects. Further, 2512 martial artists completed an online questionnaire and also had a higher health-related quality of life than the representative standard group. While both the Present and Online martial arts groups had a significantly better perceived healthrelated quality of life than the Standard group, specific differences were observed between the Present and Online groups. Different periods of when the questionnaires were administered and differences in the composition of the groups likely account for disparities in the results. Despite these differences, the study shows that people who practice martial arts consider their health-related quality of life to be better than people who did not practice a martial art. Thus, martial arts appear to benefit a person's subjective perspective of their health. 
Potential disadvantages of martial arts, such as increased violent or aggressive behavior and increased risk of injury, have been disproved by other studies. The results of this study indicate that martial arts are suitable as a primary prevention method. However, establishing that the practice of Asian martial arts improves a person's overall health must be confirmed with additional studies using objective physical and psychological parameters.

\section{Acknowledgement:}

We thank Christoph Roth for his assistance in performing the statistic evaluation, Simon Herdt for IT support related to online research, and Katrin Görg for translation support.

\section{Conflict of interests:}

The corresponding author is a martial artist and declares that there are no conflicts of interests.

\section{References}

Binder B. (2007) Psychosocial Benefits of the Martial Arts: Myth or Reality? International Ryuku Karate Research Society`s Journal

Bitzer-Gavornik G. \& Unterrainer H. (2006) Karate-Do und Resilienz/Kohärenz als Ausdruck psychischer Gesundheit. (Karate-Do and mental health - The salutogenetic effects of training Karate). http://www.karate-stmk.at/aktuelles/neuigkeiten_detail.php?id=00100. Accessed 14 February 2010

Bullinger M, Kirchberger I (1998) Handanweisung "SF-36 Fragebogen zum Gesundheitszustand“. Hofgrefe, Göttingen

Federal Statistical Office (2007) Health Expenditure 2007. Federal Statistical Office Bonn 2006.

http://www.destatis.de/jetspeed/portal/cms/Sites/destatis/Internet/DE/Navigation/Statistiken/ Gesundheit/Gesundheitsausgaben/Gesundheitsausgaben.psml. Accessed 14 February 2010 BMBF (2006) Richtlinien zur Förderung der Präventionsforschung zur Gesundheitsförderung und Primärprävention von älteren Menschen im Rahmen des Regierungsprogramms: Forschung für den Menschen. Federal Ministry of Education and Research. http://www.gesundheitsforschung-bmbf.de/de/1316.php. Accessed 14 February 2010 Burke DT, Barfoot K, Bryant S, Schneider JC, Kim HJ, Levin G (2003) Effect of implementation of safety measures in tae kwon do competition. Department of Physical 
Medicine and Rehabilitation. Harvard Medical School Bosten. MA Br J Sports Med 2003; 37 (5): 401-404

Dolin A, Popow G, Tolstikow W (1988) Kempo - Die Kunst des Kampfes - Ostasiatische Kampfsportarten. Sportverlag Berlin

Dorschner BW, Preuß HR (2005) Kampfsport - Stärkung für Geist und Seele - Religiöse und spirituelle Aspekte verschiedener Kampfsportarten. Seminar skilled work at the Christian Secondary School in Jena

SPD/Greens (2005) Draft bill of the factions Sozial Democrates Party (SPD) and BÜNDNIS 90/Die Grünen (Greens) in case of fortification of sanitary prevention from 15th February 2005 printing 15/ 4833

Grabert KI (2001) Karate-Do und Gewaltverbrechen. Report-Psychologie 26(10) Deutscher Psychologen, Bonn

Held A (2004) Traditionelles Taekwondo: eine Kampfkunst und ihre Wirkungen. Dissertation at the department of sport science of the Technical University Munich. Books on Demand, Norderstedt

Hoffmann H (2006) Untersuchung auf Aggressionswerte unter Berücksichtigung sozilogischer und sportpädagogischer Aspekte in Kampfstilen mit Trefferwirkung. Dissertation at the philosophical department IV of the institution of sport science at the Humboldt University Berlin

Kongsved SM, Basnov M, Holm-Christensen K, Hjollund NH (2007) Response Rate and Completeness of Questionnaires: A Randomized Study of Internet Versus Paper-and-Pencil Versions J Med Internet Res 2007;9(3):e25

Kral K (2009) Gesundheitsbezogene Wirkungen von asiatischen Kampfkünsten am Beispiel der Sportart Karate in Österreich. Dissertation, Sport Science Faculty, University of Wien Parzeller M, Raschka C (2003) Auswertung von 2969 Todesfällen im Vereinsport anhand einer 20jährigen Erhebung. German magazine for sports medicine, year 54 number 7/8 P01442003

Riemann K, Gläser K. (2001) Evaluation der präventiven Kurse der IKK Baden-Württemberg. Prävention 1/2001

Rosenbrock R (2008) Primärprävention - Was ist das und was soll das?" Serial of the group of researchers Public Health, Center of Science Berlin for social research (WZB). http://skylla.wz-berlin.de/pdf/2008/i08-303.pdf. Accessed 14 February 2010 
TKK (2006) Informationen über Prävention- Gesundheitskurse- Angebote- QualitätKostenerstattung. Techniker Krankenkasse (TKK), Health insurance of engineers, Flyer $10.2 / 24310 / 06 \mathrm{~V}$

Szabo P (2001) The psychologiacal impact of training deprivation in martial artists. Psychology of Sport and Exercise, 2 (3), 187-199

Head organization of health insurances (2008) Collective fields of action on primary prevention. http://www.physio.de/zulassung/pp4.htm. Accessed 14 February 2010 Terry CL (2006) Examining the relationship between global self-worth and the domainspecific perceptions of competence for children in karate, Dissertation, Alliant International University, Fresno

WHO (1986) Ottawa Charter for Health Promotion. World Health Organization. http://www.euro.who.int/AboutWHO/Policy/20010827_2. Accessed 14 February 2010.

Weiser M, Kutz I, Kutz S, Jacobson WD (1995) Psychotherapeutic Aspects of the Martial Arts. American Journal of Psychotherapy Vol. No.1 Winter 1995 118-127 Review PMID: 7762694 (PubMed - indexed for Medline)

Zetaruk MN, Violán MA, Zurakowski D, Micheli LJ (2005) Injuries in martial arts: a comparison of five styles. Br J Sports Med 2005 Jan; 39 (1): 29-33. doi: 10.1136/bjsm.2003.010322. PMID: 15618336 (PubMed -indexed for MEDLINE) Mandel P (1990) Energetische Terminalpunkt-Diagnose, Esogetics, Sulzbach 